\title{
A CRIANÇA E SEU DESENHO: UM OLHAR DA PSICOLOGIA
}

\author{
Diovana Fernandes ${ }^{1}$ \\ Yara Rodrigues de la Iglesia²
}

\section{RESUMO}

A presente pesquisa teve como objetivo estudar a evolução do desenho da criança e os possíveis desdobramentos no desenvolvimento infantil. A metodologia utilizada foi a revisão da literatura. Basicamente, a fundamentação teórica que trata sobre a evolução do grafismo foi ancorada nas obras de Georges Henri Luquet (1876-1965), Jean Piaget (1896-1980), Viktor Lowenfeld (1903-1960) e Florence de Mèredieu (1944). Para esses autores, todas as crianças passam necessariamente pelas mesmas etapas de evolução do desenho, no entanto, cada uma com características próprias. Se, por um lado, utilizam diferentes nomenclaturas para a definição dos estágios do grafismo infantil, por outro, parecem ser unânimes ao determinar que o desenho evolui segundo fases previsíveis conforme o crescimento da criança, dentro do seu processo de desenvolvimento como ser humano, levando em conta as especificidades de cada criança e suas experiências. Tendo em vista a relevância do desenho para o desenvolvimento infantil, principalmente no contexto educacional, é de fundamental importância discutir este tema. É extremamente importante que o professor conheça todas as características do desenvolvimento gráfico infantil. Esses estudos mostram que as crianças têm sua maneira própria de se expressar, de pensar, de registrar seus desejos, emoções e pensamentos. Cabe a nós, educadores, portanto, entendê-las e respeitá-las, proporcionando oportunidades de expressão, criação e experimentação.

Palavras-chave: Desenho Infantil. Psicologia. Educação Infantil.

${ }^{7}$ Acadêmica da Faculdade UNINA. Licenciada em Pedagogia. E-mail: Diovana.fernand@gmail.com

${ }^{2}$ Professora da Faculdade UNINA. Doutora em Educação na linha de Psicologia da Educação.

E-mail: yara@unina.edu.br 


\section{ABSTRACT}

This research aimed to study the evolution of children's drawing and the possible implications for child development. The methodology used was the literature review. Basically, the theoretical foundation that deals with the evolution of graphics was based on the works of Georges Henri Luquet (1876-1965), Jean Piaget (1896-1980), Viktor Lowenfeld (1903-1960) and Florence de Mèredieu (1944). To these authors, all children necessarily go through the same stages of drawing evolution, however, each with its own characteristics. If, on the one hand, they use different nomenclatures to define the phases of children's drawing, on the other, they seem to be unanimous in determining that drawing evolves in predictable stages according to the child's growth, in its development process according to a human being, taking into account the specificities of each child and their lived experiences. In view of the relevance of drawing for child development, especially in the educational context, it is fundamental importance to discuss this topic in a teacher training course. It is extremely important that the teacher knows all the characteristics of children's graphic development. These studies show that children have their own way of expressing themselves, of thinking, of registering their desires, emotions and thoughts. It is up to us educators, therefore, to understand and respect them, providing opportunities for expression, creation and experimentation.

Palavras-chave: Childish Drawing. Psychology. Child Education.

\section{INTRODUÇÃO}

Atualmente, podemos encontrar estudos de grafismos infantis que analisam o processo da criança em relação a aspectos gráficos, perceptivos e psicológicos para explicar as alterações que ocorrem em seu desenvolvimento. A ênfase desses estudos está, de modo geral, na caracterização do desenho - representação gráfica - como uma atividade natural e espontânea, dividida em estágios, etapas ou fases que seguem uma sequência universal. Trata-se dos estudos psicológicos sobre a evolução do grafismo infantil.

Não buscamos aqui sobrepor distintos paradigmas teórico-epistemológicos, mas conhecer essa perspectiva, como uma possível maneira de leitura dos grafismos infantis. Nesse sentido, a pesquisa em questão teve como objetivo estudar a evolução do desenho da criança e os possíveis desdobramentos no 
desenvolvimento infantil.

Este estudo, de caráter qualitativo, foi realizado por meio de revisão da literatura, trazendo contribuições de autores como Georges Henri Luquet (1876-1965), Jean Piaget (1896-1980), Viktor Lowenfeld (1903-1960) e Florence Mèredieu (1944), que, de modo geral, identificam e descrevem os estágios do grafismo infantil a partir de períodos de desenvolvimento cognitivo da criança. Nas descrições, são consideradas as suas produções como resultado de sua atividade de criação e imaginação e como prolongamento da percepção infantil, de expressão de si mesmo e do universo.

\section{O GRAFISMO INFANTIL POR MEIO DE ESTÁGIOS}

No início do século XIX, diversos pesquisadores ocuparam-se em analisar o grafismo infantil e o desenvolvimento da criança. De acordo com essa perspectiva desenvolvimentista, os estágios pelos quais as crianças passam são entendidos como universais, ou seja, independentemente da cultura em que a criança estiver inserida, ela vai percorrer os mesmos estágios.

Ainda que um indivíduo possa passar por eles mais depressa ou mais devagar, ele não pode saltar os estágios. Os autores que estudam o desenho infantil buscam compreender o que ocorre quando a criança desenha, e por meio dessas descobertas caracterizaram-se novas concepções pedagógicas. A maioria desses pensadores considera dividir o grafismo infantil em uma sequência de estágios, assegurando que os estágios inferiores são menos complexos e são pré-requisitos aos estágios superiores (VALENTE, 2002).

Esses estudiosos do grafismo infantil, sem exceção, reconhecem haver determinadas fases, etapas ou períodos que são comuns aos sujeitos em processo de apropriação do desenho enquanto sistema de representação. E, de fato, desde o rabisco sem intencionalidade de representação até a representação gráfico-plástica propriamente dita, podemos claramente identificar aspectos visuais invariantes no processo de apropriação do desenho como sistema semiótico de representação por parte do sujeito (ALEXANDROFF, 2010, p. 26). 
Compreender o desenho infantil por uma perspectiva de estágios não significa desrespeitar a sua forma de expressão ou acelerar o processo criativo. Segundo Sans (2007, p. 14), "O processo criativo não é o mesmo para todas as crianças. Embora obedeça a um ritmo pessoal, existem características comuns que possibilitam a sua divisão em estágios".

É relevante mencionar que as pesquisas de Lowenfeld e Brittain apresentam o grafismo infantil como meio de expressão, produto da criação e imaginação, sem levar em consideração o processo. Já estudiosos como Luquet e Piaget direcionam para uma teoria construtivista ao considerarem o desenho como objeto de conhecimento, declarando que, para compreendê-lo, a criança organiza hipóteses na sua interação com esse objeto (PILLAR, 2012).

No Trabalho de Conclusão de Curso (TCC) que deu origem a este artigo, foram abordados quatro autores que estudam a evolução do grafismo, nomeadamente: Georges Henri Luquet (1876-1965), Jean Piaget (1896-1980), Viktor Lowenfeld (1903-1960) e Florence de Mèredieu (1944). Para esses autores, todas as crianças passam necessariamente pelas mesmas etapas de evolução do desenho, no entanto cada uma delas com características próprias. Neste artigo, será abordado, principalmente, o desenvolvimento do grafismo na perspectiva de Jean Piaget.

De acordo com Piaget (1896-1980), a evolução do desenho infantil está intimamente ligada à aquisição da linguagem e da escrita, e a criança, mesmo antes de traçar verdadeiros signos, tenta imitar a escrita e o grafismo do universo adulto. Esse movimento ocorre por volta dos 3 ou 4 anos, e a criança tem plena consciência de que está desenhando com o propósito de transmitir uma mensagem.

Para o autor, a criança, ao desenhar, demonstra mais o que sabe, não necessariamente o que observa diretamente, por isso devemos levar em consideração o enunciado verbal que ela atribui à sua produção gráfica. Segundo Piaget, as crianças passam por cinco estágios do grafismo, os quais se relacionam a suas etapas de desenvolvimento infantil. (PIAGET, 1971)

A primeira dessas fases é a Garatuja, que se subdivide em: Garatuja Desordenada e Garatuja Ordenada. A segunda fase destacada por Piaget é a Pré-Esquematismo, a terceira é conhecida como Esquematismo e a última fase é 
a do Pseudonaturalismo. A seguir, será descrita cada uma das fases propostas pelo autor.

a) Garatuja: A primeira fase se subdivide em dois estágios, Garatuja Desordenada e Garatuja Ordenada, associando-se ao estágio Sensório-Motor (zero a dois anos), e parte do estágio Pré-Operatório (dois a sete anos). Nessa fase, observa-se uma concordância entre Piaget (1971) e Luquet (1969), pois ambos afirmam que a criança desenha motivada pelo prazer. De acordo com Piaget (1971), essa fase pode ser dividida em:

I. Garatuja Desordenada: Corresponde aos movimentos amplos do grafismo, com traçados simples e sem planejamento, que muitas vezes se repetem uns em cima dos outros. Neste estágio, há grande exploração por parte da criança em descobrir novas superfícies e instrumentos para desenhar. $\bigcirc$ desenho da Garatuja Desordenada, que representa um exercício motor, é mostrado a seguir, na Figura 1:

Figura 1 - Garatuja Desordenada

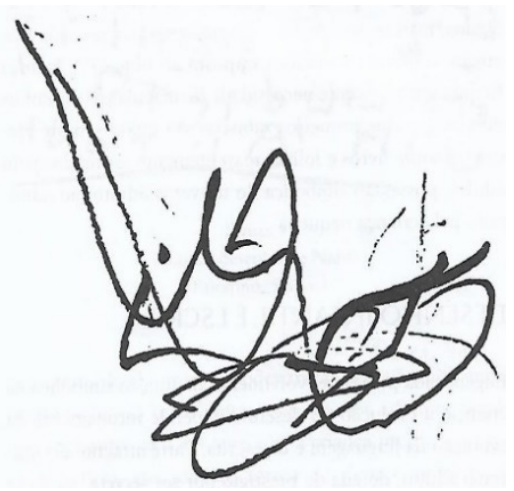

Fonte: Mèredieu (2017, p. 25)

II. Garatuja Ordenada: Neste estágio, a criança torna-se capaz de relacionar seus movimentos aos seus traçados, trocando intencionalmente as cores disponíveis. Nesse momento, ela começa a nomear seus desenhos que se caracterizam por círculos e formas, diferenciando-se pelo tamanho e a localização das figuras grafadas. É comum, por exemplo, a criança dizer que um círculo ovalado seja um cachorro e, antes de terminar o desenho, dizer que é um gato. Exemplo apresentado na Figura 2: 


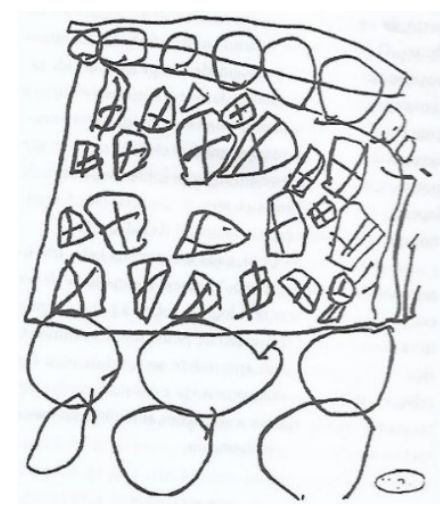

Fonte: Mèredieu (2017, p. 85)

b) Pré-Esquematismo: Inicia para a criança (final do estágio Pré-Operatório) a descoberta da relação entre desenho, pensamento e realidade, consequentemente seus traçados evoluem para formas mais reconhecíveis. Contudo, os elementos desenhados continuam dispersos, sem ligação direta entre si, pois a criança utiliza a imaginação para realizá-los. O grafismo neste estágio é mostrado a seguir, na Figura 3:

Figura 3 - Pré-Esquematismo
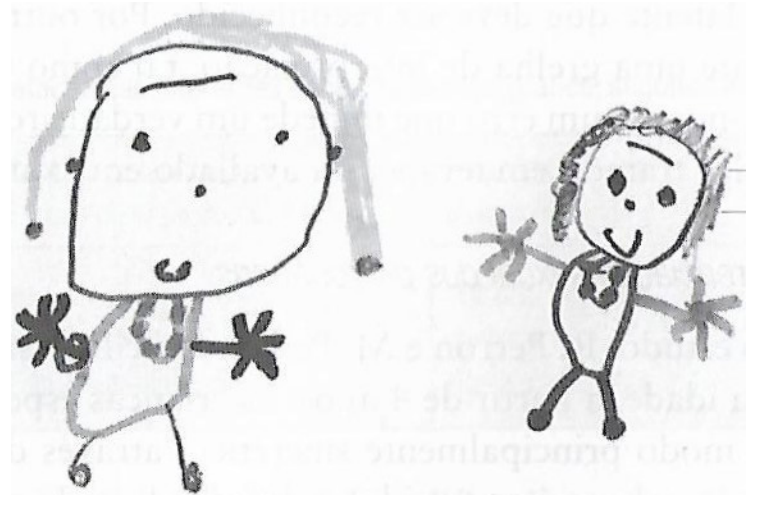

Fonte: Cognet (2019, p. 236)

c) Esquematismo: Relaciona-se ao estágio de desenvolvimento das Operações Concretas, que acontece entre os sete e dez anos, aproximadamente. O grafismo representa formas definidas, simbolizando partes do meio infantil e a relação entre esses componentes. Percebe-se a definição de formas es- 
pecíficas para determinados elementos, bem como a relação cor-objeto e o surgimento da linha de base, em que se fixam alguns itens ao chão. Ver figura 4:

Figura 4 - Esquematismo

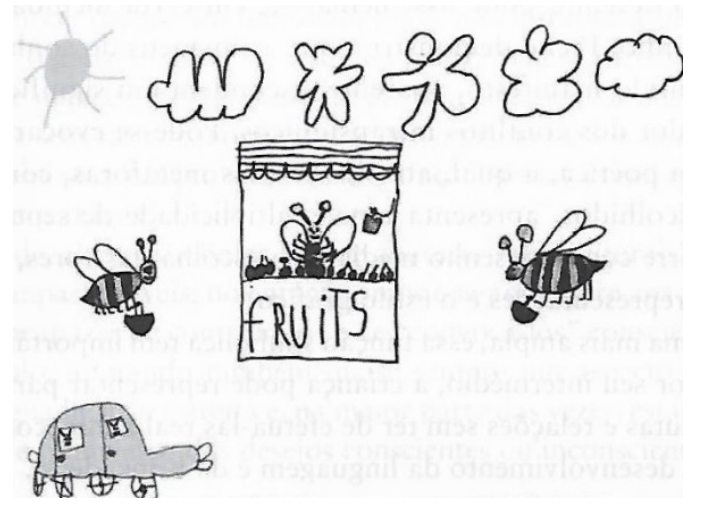

Fonte: Cognet (2019, p. 17)

d) Realismo: Este estágio caracteriza-se pelo início da diferenciação entre sexos (final do estágio das Operações Concretas), aderindo a formas geométricas mais rígidas, ao plano e à superposição, que corresponde à organização dos elementos de forma visual, tal como é encontrado na realidade. Exemplo de desenho neste estágio é apresentado a seguir, na Figura 5:

Figura 5 - Realismo

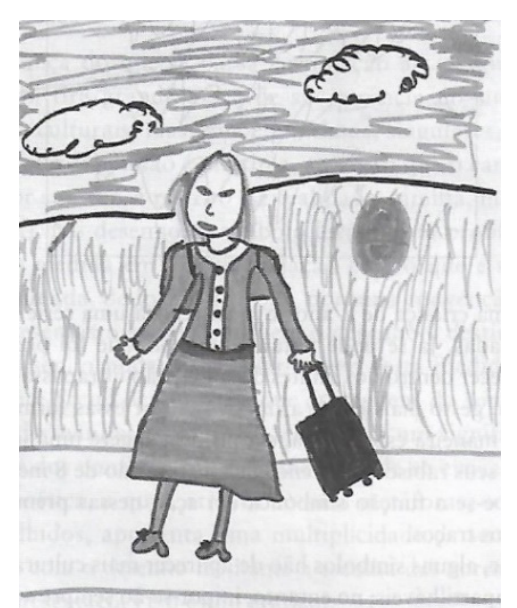

Fonte: Cognet (2019, p. 20)

e) Pseudonaturalismo: Marca-se pelo fim da arte como atividade espon- 
tânea e início da investigação de sua própria personalidade. Neste desenho, aparece a objetividade, o realismo, a profundidade, o espaço subjetivo e o uso consciente das cores. Esta etapa é correspondente ao estágio das operações abstratas, aproximadamente de dez anos em diante. A seguir, na Figura 6:

Figura 6 - Pseudo Naturalismo

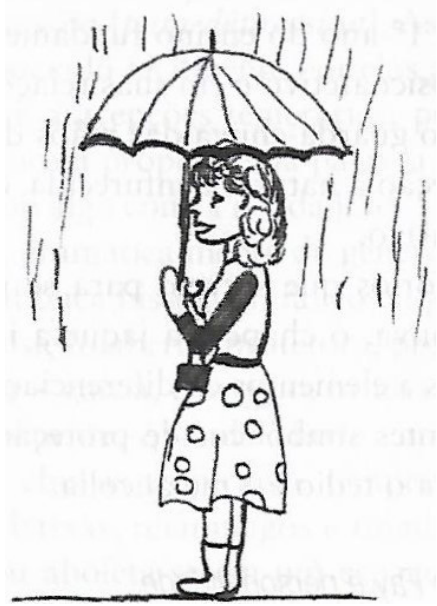

Fonte: Cognet (2019, p. 282)

Esses estágios não são imutáveis ou estáticos, existem crianças que podem apresentar características de mais de um estágio de desenvolvimento simultaneamente. Assim, devemos considerar os vários fatores que podem influenciar esse processo, como: o ambiente familiar, a situação social ou econômica e até mesmo possíveis deficiências.

Conforme Mèredieu (2017), a avaliação de uma produção infantil não deve acontecer através de uma análise isolada, pois não se pode observar o desenho de uma criança e tirar conclusões a partir de situações genéricas, uma vez que a interpretação do grafismo infantil não consegue se separar da subjetividade humana. Para a autora, devemos considerar que o conhecimento infantil somente pode ser compreendido estudando individualmente cada criança, já que nenhuma é igual a outra. O estudo das produções infantis pode possibilitar a descoberta de respostas para determinadas questões, porém não é viável analisar o grafismo sem a compreensão dos estágios de desenvolvimento infantil e da evolução dos desenhos. Um bom início seria a busca de respostas por meio da conversa com a criança. 
Já, para Lowenfeld e Brittain (1977), a arte, independentemente da idade, expressa as relações do indivíduo com seu meio, em um processo contínuo, mas dificilmente uniforme. De início, temos como referência as garatujas, que podem auxiliar na investigação do desenvolvimento emocional e físico da criança. Esses rabiscos as acompanham dos dois aos quatro anos e, se observamos maior ou menor habilidade do que é o esperado para a idade, não significa falta de talento, mas pode estar relacionado a inseguranças da criança. Geralmente, essas diferenças nos níveis das garatujas configuram mudanças psicológicas e fisiológicas. O desenho infantil é o próprio reflexo de uma criança. Mais que uma atividade agradável, é o caminho pelo qual ela concretiza alguns pensamentos e desenvolve suas relações. Apesar de existirem grandes diferenças individuais, há também certas características comuns quanto ao nível de desenvolvimento, seja na criança ou no seu grafismo.

No avanço dos estágios, com a formação dos esquemas, a criança começa a representar objetos com certa relação lógica com ela mesma, inserindo-se no próprio desenho, fator essencial no desenvolvimento psicológico infantil. Dessa forma, faz-se necessário observar várias produções gráficas de uma mesma criança para melhor compreendê-la. Ao analisar as diferenças dos grafismos esquemáticos, podemos obter uma interpretação mais profunda da sensibilidade infantil e de sua conscientização, representações que dependem de fatores biológicos, psicológicos e ambientais, além dos incentivos recebidos que cooperam nesse desenvolvimento (LOWENFELD; BRITTAIN, 1977).

No estágio do Realismo, por exemplo, há o rompimento com os esquemas e a criança se torna cada vez mais observadora. Suas produções apresentam, de maneira evidente, que ela visualiza os elementos através de suas próprias experiências, estando verdadeiramente consciente do seu meio. Neste período, a ausência de motivação pode ser a explicação das diferenças existentes nos desenhos, assim sendo os profissionais da educação devem propiciar um espaço que seja rico e estimulante de modo que cada criança desenvolva toda sua capacidade. 
[...] Um número cada vez maior de pessoas reconhece que a aptidão de aprendizagem difere de uma idade para outra e de um indivíduo para o outro, e que essa aptidão para aprender envolve não só capacidade intelectual, mas também fatores sociais, emocionais, perceptuais, físicos e psicológicos. O processo de aprendizagem é muito complexo e, portanto, talvez não exista um único método de ensino que se possa considerar o "melhor" (LOWENFELD; BRITTIAN, 1977, p. 15).

O grafismo infantil pode, assim, ser utilizado como estratégia pedagógica, desenvolvido de maneira transversal, pois o educador, ao observar a produção de uma criança, pode aprender muito sobre seus comportamentos, atitudes e formas de pensar.

Sendo assim, o docente não deve conferir sentimentos ou conceitos aos desenhos infantis, como: bom, precisa melhorar, não gostei. É importante que as instituições de ensino, principalmente na Educação Infantil, compreendam e valorizem a atividade do grafismo. Os profissionais da educação e os pais têm de, por sua vez, ter um olhar sensível ao analisar o desenho e decodificar a mensagem que a criança pretende comunicar.

A prática do grafismo como vimos é extremamente importante no dia a dia das instituições de Educação Infantil, além de ser algo prazeroso para a criança. Desse modo, o desenho deve ser compreendido de maneira mais significativa e abrangente nas escolas de Educação Infantil e merece ser valorizado como mais que simples rabiscos, sendo verdadeiramente reconhecido como um instrumento que auxilia os educadores a compreenderem o desenvolvimento infantil.

\section{CONSIDERAÇÕES FINAIS}

O referencial teórico foi fundamentado em autores que consideram as produções infantis como um momento da evolução mental da criança, visto que as características dos grafismos infantis mantêm correlação com o desenvolvimento cronológico da criança. O desenvolvimento progressivo do desenho implica mudanças significativas no desenvolvimento da criança.

Qualquer que seja a nomenclatura usada para definir o desenho infantil, ele evolui conforme o crescimento da criança dentro do seu processo de de- 
senvolvimento como ser humano. As etapas, fases ou estágios devem ser vividos pelas crianças, um a um, para que não surja posteriormente uma lacuna no seu desenvolvimento (NOVAES; NEVES, 2004).

Pode-se concluir que o desenho infantil é uma das principais manifestações gráficas da criança. A linguagem gráfica, tal como a oral, é uma das formas que a criança tem de se comunicar com os outros. Por meio dela, a criança mostra o seu próprio modo de pensar, aprender e brincar. Deve-se ressaltar, ainda, a possibilidade expressiva envolvida no ato de desenhar, que, para a criança, torna-se uma ferramenta para manifestar sua imaginação e afetividade.

Por meio da revisão da literatura, ficou evidente que o grafismo infantil não é uma reprodução mecânica da realidade perceptiva adulta, mas um meio único de percepção de mundo. Portanto, o repertório gráfico está condicionado pelo meio social em que a criança está inserida. Dentro dessa lógica, a prática do desenho assume o papel de impulsionador do processo de desenvolvimento infantil, bem como um relevante meio de intercâmbio social.

Conclui-se que estudar o grafismo infantil pode oportunizar aos profissionais da Educação Infantil um entendimento significativo sobre os aspectos cognitivos e emocionais da criança. Em vista disso, entendemos que a função dos professores não se limita ao fornecimento de materiais diversos para as crianças, como um passatempo, sem a devida contextualização, mas sim propiciar práticas que estimulem e favoreçam o pensamento criativo. Isso porque é por meio dos rabiscos e traçados que o professor tem a oportunidade de compreender o desenvolvimento intelectual e emocional de cada criança, aprender mais sobre a construção dos seus pensamentos e analisar sua forma de conhecer o mundo.

Podemos constatar que o desenvolvimento do grafismo infantil é uma questão muito relevante, porém pouco estudada e ainda pouco conhecida por docentes da Educação Infantil, fato verificado na dificuldade de encontrar produções cientificas sobre o tema. A partir do nosso ponto de vista, a falta de maiores conhecimentos sobre o grafismo infantil pode levar a intervenções pouco adequadas por parte dos profissionais da Educação Infantil, oferecendo, por exemplo, modelos de desenhos prontos e estereotipados ou fazendo co- 
branças que não condizem com a idade da criança. Entendemos que é importante conhecer mais sobre este tema, seja pela atenta observação do cotidiano junto às crianças ou a partir de leituras específicas.

De modo geral, espera-se que este trabalho possa contribuir com a discussão sobre o desenho infantil. No entanto, não tivemos a pretensão de findar a discussão sobre o tema. Espera-se que outras pesquisas possam ser realizadas de modo a ampliar os conhecimentos referentes a este assunto de tão grande significância no contexto educacional.

\section{REFERÊNCIAS}

ALEXANDROFF, Marlene Coelho. Os caminhos paralelos do desenvolvimento do desenho e da escrita. Construção psicopedagógica, São Paulo, v. 18, n. 17, p. 20-41, 2010.

COGNET, Georges; COGNET, Anna. Compreender e interpretar desenhos infantis. 3. ed. Rio de Janeiro: Vozes, 2019.

LOWENFELD, Viktor; BRITTAIN, William Lambert. Desenvolvimento da capacidade criadora. São Paulo: Mestre Jou, 1977.

LUQUET, Georges Henri. O desenho infantil. Porto: Civilização, 1969.

MÈREDIEU, Florence. O desenho infantil. 12. ed. São Paulo: Cultrix, 2017.

NOVAES, Ema Roseli de; NEVES, Lygia Helena Roussenq. A Criança e o Desenho Infantil: a Sensibilidade do Educador Mediante uma Produção Artística Infantil. Revista de Divulgação Técnico-Cientifica do ICPG, 2, 5, 2004.

PIAGET, Jean. A formação do símbolo na criança: imitação, jôgo e sonho imagem e representação. 3. ed. Rio de Janeiro: Zahar, 1971.

PILLAR, Analice Dutra. Desenho e escrita como sistemas de representação. Porto Alegre: Penso, 2012.

SANS, Paulo de Tarso Cheida. Pedagogia do desenho infantil. 2 ed. Campinas: Alínea, 2007.

VALENTE, Maria Odete. A Educação para os Valores. In: PIRES, Eurico Lemos, et al. 0 Ensino Básico em Portugal. Rio Tinto: ASA, 2002. 